\title{
A Supplement Supporting Appetite Based on Olfactory Stimulation
}

\author{
J. Mejzlik ${ }^{1, *}$, N. Kossuthova ${ }^{1}$, K. Skalova ${ }^{1}$, L. Skoloudik ${ }^{1}$, M. Cerny $^{1}$, V. Chrobok $^{1}$, V. Pellantova ${ }^{2}$ \\ ${ }^{1}$ Department of Otorhinolaryngology and Head and Neck Surgery, University Hospital Hradec Kralove, \\ Charles University, Faculty of Medicine in Hradec Kralove, Czech Republic \\ ${ }^{2}$ Department of Infectious Diseases, University Hospital Hradec Kralove, Charles University, \\ Faculty of Medicine in Hradec Kralove, Czech Republic \\ *Corresponding author: Jan.Mejzlik@hotmail.com
}

Received June 07, 2019; Revised July 14, 2019; Accepted July 29, 2019

\begin{abstract}
An olfactory supplements are used to influence the smell of foodstuffs in such a way as to make them olfactorily more attractive. The authors suggest the supplement for olfactory stimulation in patients with parenteral nutrition. The 25 panellists did not know what aromata were contained in the bottles, their concentrations, or the number of different samples presented to the panel. The aromata of the olfactory supplement were selected in such a way as to cover, due to its popularity, all spectrum of panellists: smoked ham, tangerine, Niva cheese and placebo. The parameters were evaluated either visually by an analogue scale from -10 to +10 : pleasantness, smell, the sensation produced by the supplement, or the selection of the best corresponding verbal descriptor of the smell. The data were evaluated statistically. Comparison of the set was performed using the Mann-Whitney $U$ test at the level of significance of alpha 0.05 . All aromata under evaluation differed statistically significantly from placebo. Of the offered possibilities, however, only Tangerine was evaluated as pleasant: Z(4.5) for the supplement concentration of $1 \%$ and/or Z (5.2) for the $0.3 \%$ solution. The pleasantness of Niva cheese and smoked ham aromata were evaluated as not statistically different from placebo. No difference was found in olfactory preference in males and females.
\end{abstract}

Keywords: olfactory stimulation, sensory panel, nutrition, food, olfactory supplement

Cite This Article: J. Mejzlik, N. Kossuthova, K. Skalova, L. Skoloudik, M. Cerny, V. Chrobok, and V. Pellantova, "A Supplement Supporting Appetite Based on Olfactory Stimulation." Journal of Food and Nutrition Research, vol. 7, no. 7 (2019): 537-542. doi: 10.12691/jfnr-7-7-8.

\section{Introduction}

New pieces of knowledge indicate that nutrition through an oesophageal probe or percutaneous endoscopic gastrostomy (PEG) especially in geriatric and severely ill patients may result in the prevention of aspiration with subsequent respiratory infections. In patients with this type of nutrition there is a lack of stimulation of the olfactory epithelium by aroma and the oral mucous membrane by taste. [1] The stimulation of smell increases the quality of life of patients with head and neck cancer. [2] Moreover, if the olfactory or gustatory epithelium are stimulated, there occurs, besides increased activity of the upper swallowing tract [3,4,5], also an increase in blood flow through the digestive system, without necessary swallowing of food, which demonstrates that stimulation of the senses of smell or taste operates independently of stimulation of the abdomen or intestine by the swallowed food. [6] With regard to this, it can be expected that artificial support of the sense of smell and appetite improves intake of food, which is important especially in patients with feeding tube. [7]
Stimulating the sense of smell and appetite by means of food induces increased formation of saliva and other digestive agents. There are substantially more experiments dealing with the theme of the influence of the taste of foodstuffs on digestion than those dealing with the influence of aroma on the digestive process. [8] The present trial aims to propose such an olfactory supplement which could be used to stimulate the sense of smell in patients with food intake disorders, for example patients who are fed parenterally or by a feeding probe. In this group of patients when receiving food the olfactory sensation, which is the physiological stimulator of digestive functions, is eliminated. The introductory experiment focuses on the development of the form, composition and concentration of an olfactory supplement. After receiving the proper set of aromata, the experiments will continue in clinical nutritional studies. In future the use of a supplement is planned for patients with food intake disorders, primarily oncological patients with tumours of the head and neck during and after treatment.

\section{Methods}

Design: randomized double-blind clinical trial. 
Ethics: We declare that the study have been approved by the Ethical Committee of University hospital Hradec Kralove and have therefore been performed in accordance with the ethical standards laid down in the 1964 Declaration of Helsinki and its later amendments.

The substance tested: an olfactory supplement

The olfactory supplement which is being tested is a dietary supplement employed to influence the aroma of foodstuffs to make them "olfactorily more attractive". These supplements are routinely used substances employed to season the final products of food industry. Of the offered variants, the following aromata were selected:

1. Smoked ham

2. Tangerine

3. Niva cheese

4. Placebo (without aroma).

The below-mentioned amounts of the olfactory supplement were ordered and supplied by a firm for the trial. Two concentrations of each aroma were employed.

1. 10 times smoked ham $100 \mathrm{mg}$

2. 10 times smoked ham $300 \mathrm{mg}$

3. 10 times tangerine $100 \mathrm{mg}$

4. 10 times tangerine $300 \mathrm{mg}$

5. 10 times Niva cheese $100 \mathrm{mg}$

6. 10 times Niva cheese $300 \mathrm{mg}$

7. 10 times an empty bottle - placebo - thus just for water

Form of application: microemulsion in a 50 microlitre spray applicator. Each applicator is labelled with a random four-digit number.

Preparation: Olfactory stimulators were manufactured in the form of microgranules, on the surface of which an active substance was bound. They were supplied in a powdered form. Distilled water was used to dilute the olfactory supplements and served also as placebo. Not later than 2 hours prior to the beginning of the sensory panel, water was supplemented into prepared small bottles up to the gauge line of $100 \mathrm{ml}$, which achieved the required concentration. The solution prepared in this manner was not stabilized by any other chemical substance which would influence the olfactory sensation. It was not biologically stabilized either and had to be consumed on the same day. The used small bottles were destroyed after the trial.

Concentration of the olfactory supplement was selected in such a manner as to make the olfactory sensations very low and thus the minimal stimulatory concentration could not be exceeded. In order to verify the efficiency, the concentrations of $0.1 \%$ and $0.3 \%$ were selected. In each of the aromata 1-4, 2 concentrations were tested, i.e. altogether 8 aromata (including placebo). The panel always received 2 samples of each aroma and concentration, i.e. altogether 16 samples - with different random numbers. The amount of placebo 4 was employed because of the statistical equality of the sets. If wanting to evaluate, e.g., Tangerine $(0.1$ as well as $0.3 \%)$ versus placebo, the number in the placebo branch would have to be sufficient.

\section{Panel of Experts}

Methodology of testing was used according to [9]

The tested supplement was presented to physicians employed at the Clinic of Otorhinolaryngology and Head and Neck Surgery and the students of general medicine, who had been instructed in advance what they should evaluate in the tested sample. To avoid the bias, the panellists did not know what aromata were contained in the small bottles, what their concentrations were, or how many different samples were presented to the panel.

The panellists had to comply with the following criteria:

1. They must not suffer from a respiratory infection or a disease which impairs olfaction

2. They must not chew a chewing gum 30 minutes prior to testing

3. They must not eat spicy food prior to testing

4. On the day of testing they must not use perfume

5. On the day of testing they can use only an unperfumed deodorant

6. Prior to testing they must not use perfumed cosmetics, soaps, eau-de-Cologne, etc.

7. They must not have smelling compounds (disinfection) on their hands

8. They must not wear smelling clothes (medical personnel uniform is enough)

9. They must keep confidentiality of the panel

10. They must not influence other panellists by comments on the given sample

Each panellist was issued a random number and a form in which he/she evaluated the assigned samples. Each form included 8 items marked with random numbers. For each item the same parameters were evaluated.

\subsection{Parameters under Evaluation}

Pleasantness is subjective and is evaluated on a step scale by means of a visually analogue model $(-10,0,+10)$.

Unpleasant - $10-9-8-7-6-5-4-3-2-10+1+2+3+4$ $+5+6+7+8+9+10$ Pleasant.

\subsection{Characteristics of Aroma}

Panellists were to select a taste similar to the given supplement.
1. Salty
2. Sweet
3. Bitter
(faintly $0+1+2+3+4+5$ strongly)
4. Sour
(faintly $0+1+2+3+4+5$ strongly)
5. None
(faintly $0+1+2+3+4+5$ strongly)
(faintly $0+1+2+3+4+5$ strongly)
(faintly $0+1+2+3+4+5$ strongly)

\subsection{Characteristics of the Sensation Induced by the Supplement:}
1. Tingling
2. Itching
3. Warm
(faintly $0+1+2+3+4+5$ strongly)
4. Burning
5. Pungent
6. Sharp
7. Cool
8. Metallic
(faintly $0+1+2+3+4+5$ strongly)
(faintly $0+1+2+3+4+5$ strongly)
(faintly $0+1+2+3+4+5$ strongly)
(faintly $0+1+2+3+4+5$ strongly)
(faintly $0+1+2+3+4+5$ strongly)
(faintly $0+1+2+3+4+5$ strongly)
(faintly $0+1+2+3+4+5$ strongly)

\subsection{Recognized Descriptors of Aroma}

Panellists of each offered group of aromata selected at least one which according to their opinion was most similar to the presented supplement. 
1. Floral

Almond, cinnamon, coconut, eucalyptus, fragrant, herbal, lavender, perfume, rose-like, spicy, vanilla

2. Fruity

Apple, cherry, citrus, cloves, grapes, lime, melon, maple, melon, minty, orange, strawberry

3. Medicinal

Alcohol, ammonia, anaesthetic, camphor, chlorinous, disinfectant, menthol, soapy, vinegar

4. Chemical

Car exhaust, cleaning liquids, creosote, gasoline, grease, kerosene, molasses, mothball, oil, paint, petroleum, plastic, solvent, sulphur, tar, turpentine, varnish, vinyl

5. Fishy

Ammine, dead fish, perm solution

6. Offensive

Blood, burn, decay, fecal, garbage, manure, putrid, rancud, raw meat, rotten eggs, septic, sewer, sour, urine, vomit

7. Earthy

Ashy, chalk like, grassy, mold, mouse like, mushrooms, musky, musty, peat like, pine, smokey, stale, swampy, woody, yeast

8. Vegetable

Celery, cucumber, dill, garlic, green pepper, nutty, onion

\subsection{Statistical Evaluation}

Statistical evaluation used the programme Statistica: version 13.2. All the mentioned parameters of tested samples were compared with placebo (saline solution). Distribution of the values in the set did not show normal distribution; that is why the non-parametric MannWhitney U test was used for the sake of comparison. Statistical significance was evaluated on the level of $\alpha=0.05$. The $Z$ coefficient shows how many times the average monitored parameter was higher/lower than the identical parameter of placebo. The $p$ value shows statistical significance. Statistically significant values of $\mathrm{p}<0.05$ are in red.

\section{Results}

The results are depicted in tables $1 .-6$. A $0.1 \%$ solution containing tangerine aroma was compared with placebo. Even this very low concentration of aroma possesses a clearly dominating pleasant sour and stimulating tone, which dominates with the descriptors: floral and fruity. Table 1.

A $0.3 \%$, solution containing tangerine aroma was also compared with placebo. A clearly dominating pleasant sweet, sour, fruity and stimulating tone. A number of panellists surprisingly classified the aroma as vegetables. Table 2.

A $0.1 \%$ solution containing smoked ham aroma was compared with placebo. In the evaluation of the supplement there dominate the items salty, irritating, pervasive, sharp, earthy and repulsive character. Table 3.

Higher concentration, a $0.3 \%$ solution containing smoked ham aroma was also compared with placebo. In the evaluation of the supplement there dominate the items salty, stimulating, pervasive, sharp, earthy and repulsive character. The evaluation does not differ too much from the supplement with the low concentration of the aroma. Table 4.

Table 1. Mann-Whitney U test. A $0.1 \%$ solution containing tangerine aroma in comparison with placebo. Even this very low concentration of aroma possesses a clearly dominating pleasant sour and stimulating tone

Tangerine 0,1\%. Mann-Whitney U Test,

Marked tests are significant at $\mathrm{p}<, 05000$

\begin{tabular}{|l|c|c|}
\hline & Z & p-value \\
\hline Pleasantness & $-4,49176$ & 0,000007 \\
\hline Salty & 0,26194 & 0,793369 \\
\hline Sweet & $-3,28878$ & 0,001006 \\
\hline Bitter & $-0,46567$ & 0,641453 \\
\hline Sour & $-3,26938$ & 0,001078 \\
\hline None & 2,26043 & 0,023795 \\
\hline Tingling & $-1,27089$ & 0,203770 \\
\hline Itching & $-2,52237$ & 0,011657 \\
\hline Warm & $-0,74701$ & 0,455058 \\
\hline Burning & 0,00970 & 0,992260 \\
\hline Pungent & $-3,30819$ & 0,000939 \\
\hline Sharp & $-0,97014$ & 0,331976 \\
\hline Cool & $-2,87162$ & 0,004084 \\
\hline Metalic & $-0,25224$ & 0,800858 \\
\hline Floral & $-2,53207$ & 0,011340 \\
\hline Fruity & $-4,76340$ & 0,000002 \\
\hline Medicinal & $-1,23208$ & 0,217920 \\
\hline Chemical & $-0,04851$ & 0,961312 \\
\hline Fishy & $-0,00970$ & 0,992260 \\
\hline Offensive & $-0,74701$ & 0,455058 \\
\hline Earthy & $-0,17463$ & 0,861374 \\
\hline Vegetable & $-0,74701$ & 055058 \\
\hline & & \\
\hline & & \\
\hline & -192 & 0 \\
\hline
\end{tabular}

Table 2. Mann-Whitney $U$ test. A $0.3 \%$, solution containing tangerine aroma in comparison with placebo. A clearly dominating pleasant sweet, sour, fruity and stimulating tone. A number of panellists surprisingly classified the aroma as vegetables

Tangerine $0,3 \%$. Mann-Whitney U Test,

Marked tests are significant at $\mathrm{p}<, 05000$

\begin{tabular}{|l|c|c|}
\hline & $\mathrm{Z}$ & $\mathrm{p}$-value \\
\hline Pleasantness & $-5,23877$ & 0,000000 \\
\hline Salty & 0,50447 & 0,613929 \\
\hline Sweet & $-3,71565$ & 0,000203 \\
\hline Bitter & $-0,46567$ & 0,641453 \\
\hline Sour & $-4,00669$ & 0,000062 \\
\hline None & 2,26043 & 0,023795 \\
\hline Tingling & $-0,78582$ & 0,431976 \\
\hline Itching & $-1,04775$ & 0,294753 \\
\hline Warm & $-0,49477$ & 0,620761 \\
\hline Burning & 0,00970 & 0,992260 \\
\hline Pungent & $-3,89027$ & 0,000100 \\
\hline Sharp & $-0,97014$ & 0,331976 \\
\hline Cool & $-2,54177$ & 0,011030 \\
\hline Metalic & 0,00000 & 1,000000 \\
\hline Floral & $-2,04700$ & 0,040659 \\
\hline Fruity & $-4,97683$ & 0,000001 \\
\hline Medicinal & $-1,25000$ & 0,211300 \\
\hline Chemical & 0,23283 & 0,815890 \\
\hline Fishy & $-0,25224$ & 0,800858 \\
\hline Offensive & $-0,26194$ & 0,793369 \\
\hline Earthy & $-0,23283$ & 0,815890 \\
\hline Vegetable & $-0,97014$ & \\
\hline & & 0,331976 \\
\hline & & \\
\hline
\end{tabular}


Table 3. Mann-Whitney $U$ test. A $0.1 \%$ solution containing smoked ham aroma in comparison with placebo. In the evaluation of the supplement there dominate the items salty, irritating, pervasive, sharp, earthy and repulsive character

\begin{tabular}{|l|c|c|}
\hline \multicolumn{3}{|l|}{$\begin{array}{l}\text { Smoked Ham 0,1\%. Mann-Whitney U Test, } \\
\text { Marked tests are significant at } \mathrm{p}<, 05000\end{array}$} \\
\hline & Z & p-value \\
\hline Pleasantness & $-0,59179$ & 0,553994 \\
\hline Salty & $-4,25893$ & 0,000021 \\
\hline Sweet & $-0,02910$ & 0,976781 \\
\hline Bitter & $-0,23283$ & 0,815890 \\
\hline Sour & $-0,50447$ & 0,613929 \\
\hline None & 1,97909 & 0,047807 \\
\hline Tingling & $-0,76641$ & 0,443431 \\
\hline Itching & $-2,76491$ & 0,005694 \\
\hline Warm & $-1,24178$ & 0,214318 \\
\hline Burning & $-1,15447$ & 0,248309 \\
\hline Pungent & $-2,78431$ & 0,005365 \\
\hline Sharp & $-1,69775$ & 0,089556 \\
\hline Cool & 0,65000 & 0,515696 \\
\hline Metalic & $-0,25224$ & 0,800858 \\
\hline Floral & $-0,70820$ & 0,478819 \\
\hline Fruity & 0,21343 & 0,830991 \\
\hline Medicinal & $-0,49477$ & 0,620761 \\
\hline Chemical & $-1,04775$ & 0,294753 \\
\hline Fishy & $-0,77000$ & 0,441300 \\
\hline Offensive & $-2,45446$ & 0,014110 \\
\hline Earthy & $-2,38655$ & 0,017008 \\
\hline Vegetable & $-1,52312$ & 0,127729 \\
\hline & & \\
\hline & & \\
\hline
\end{tabular}

Table 4. Mann-Whitney U test. A $0.3 \%$ solution containing smoked ham aroma in comparison with placebo. In the evaluation of the supplement there dominate the items salty, stimulating, pervasive, sharp, earthy and repulsive character. The evaluation does not differ too much from the supplement with the low concentration of the aroma

Smoked ham 0,3\%. Mann-Whitney U Test,

Marked tests are significant at $\mathrm{p}<, 05000$

\begin{tabular}{|l|c|c|}
\hline & Z & $\mathrm{p}$-value \\
\hline Pleasantness & $-0,84402$ & 0,398657 \\
\hline Salty & $-4,96713$ & 0,000001 \\
\hline Sweet & $-0,54328$ & 0,586938 \\
\hline Bitter & $-0,94104$ & 0,346686 \\
\hline Sour & $-0,72761$ & 0,466855 \\
\hline None & 2,53207 & 0,011340 \\
\hline Tingling & $-0,50447$ & 0,613929 \\
\hline Itching & $-2,26043$ & 0,023795 \\
\hline Warm & $-1,74626$ & 0,080767 \\
\hline Burning & $-1,66865$ & 0,095189 \\
\hline Pungent & $-3,38580$ & 0,000710 \\
\hline Sharp & $-1,45521$ & 0,145611 \\
\hline Cool & 0,72761 & 0,466855 \\
\hline Metalic & $-0,25224$ & 0,800858 \\
\hline Floral & $-1,19328$ & 0,232762 \\
\hline Fruity & $-0,02910$ & 0,976781 \\
\hline Medicinal & $-0,70820$ & 0,478819 \\
\hline Chemical & $-0,82462$ & 0,409587 \\
\hline Fishy & $-0,99925$ & 0,317676 \\
\hline Offensive & $-3,44401$ & 0,000573 \\
\hline Earthy & $-1,35820$ & 0,174401 \\
\hline Vegetable & $-2,00819$ & 0,044623 \\
\hline
\end{tabular}

A $0.1 \%$ solution containing Niva cheese aroma was compared with placebo. This very low aroma concentration also possesses a clearly dominating salty, pervasive, earthy, sharp, sweet and slightly repulsive character. Table 5 .
A $0.3 \%$ solution containing Niva cheese aroma was compared with placebo. With the increased concentration of the aromatic substance in the supplement there occurred a marked difference between the tested substance and the placebo. Salty, pervasive, earthy and slightly repulsive character dominates.

Table 5. Mann-Whitney $U$ test. A $0.1 \%$ solution containing Niva cheese aroma in comparison with placebo. This very low aroma concentration also possesses a clearly dominating salty, pervasive, earthy, sharp, sweet and slightly repulsive character

Niva cheese $0,1 \%$. Mann-Whitney U Test,

Marked tests are significant at $\mathrm{p}<05000$

\begin{tabular}{|l|c|c|}
\hline Marked tests are significant at $\mathrm{p}<, 05000$ & $\mathrm{p}$-value \\
\hline Pleasantness & $\mathrm{Z}$ & 0,938137 \\
\hline Salty & $-0,07761$ & 0,050033 \\
\hline Sweet & $-1,95969$ & 0,007857 \\
\hline Bitter & $-2,65819$ & 0,351680 \\
\hline Sour & $-0,93134$ & 0,082467 \\
\hline None & $-1,73656$ & 0,045664 \\
\hline Tingling & 1,99849 & 0,303786 \\
\hline Itching & $-1,02835$ & 0,069653 \\
\hline Warm & $-1,81417$ & 0,620761 \\
\hline Burning & $-0,49477$ & 0,823432 \\
\hline Pungent & $-0,22313$ & 0,000817 \\
\hline Sharp & $-3,34699$ & 0,331976 \\
\hline Cool & $-0,97014$ & 0,236583 \\
\hline Metalic & $-1,18357$ & 1,000000 \\
\hline Floral & 0,00000 & 0,240447 \\
\hline Fruity & $-1,17387$ & 0,125320 \\
\hline Medicinal & $-1,53283$ & 0,478819 \\
\hline Chemical & $-0,70820$ & 0,785899 \\
\hline Fishy & $-0,27164$ & 0,802588 \\
\hline Offensive & $-0,25000$ & 0,050033 \\
\hline Earthy & $-1,95969$ & 0,082467 \\
\hline Vegetable & $-1,73656$ & 0,225254 \\
\hline & $-1,21268$ & \\
\hline
\end{tabular}

Table 6. Mann-Whitney $U$ test. A $0.3 \%$ solution containing Niva cheese aroma in comparison with placebo. With the increased concentration of the aromatic substance in the supplement there occurred a marked difference between the tested substance and the supplement. Salty, pervasive, earthy and slightly repulsive character dominates

Nive cheese $0,3 \%$. Mann-Whitney U Test,

Marked tests are significant at $\mathrm{p}<, 05000$

\begin{tabular}{|c|c|c|}
\hline \multirow[t]{2}{*}{ variable } & \multicolumn{2}{|c|}{$\begin{array}{c}\text { Mann-Whitney U Test (Redukce placeba NK_KS.sta) } \\
\text { By variable Ammount } \\
\text { Marked tests are significant at } \mathrm{p}<, 05000\end{array}$} \\
\hline & $\mathrm{Z}$ & $\mathrm{p}$-value \\
\hline Pleasantness & 1,80447 & 0,071159 \\
\hline Salty & $-3,68654$ & 0,000227 \\
\hline Sweet & $-1,32910$ & 0,183818 \\
\hline Bitter & $-0,95074$ & 0,341737 \\
\hline Sour & $-0,99925$ & 0,317676 \\
\hline None & 1,99849 & 0,045664 \\
\hline Tingling & $-0,97014$ & 0,331976 \\
\hline Itching & $-3,62833$ & 0,000285 \\
\hline Warm & $-0,99925$ & 0,317676 \\
\hline Burning & $-0,23283$ & 0,815890 \\
\hline Pungent & $-4,45295$ & 0,000008 \\
\hline Sharp & $-1,69775$ & 0,089556 \\
\hline Cool & 0,65000 & 0,515696 \\
\hline Metalic & $-0,48507$ & 0,627626 \\
\hline Floral & $-0,69850$ & 0,484863 \\
\hline Fruity & $-0,27164$ & 0,785899 \\
\hline Medicinal & $-0,73731$ & 0,460935 \\
\hline Chemical & $-1,34850$ & 0,177499 \\
\hline Fishy & $-0,70820$ & 0,478819 \\
\hline Offensive & $-2,20222$ & 0,027650 \\
\hline Earthy & $-3,03655$ & 0,002393 \\
\hline Vegetable & $-0,74701$ & 0,455058 \\
\hline
\end{tabular}




\section{Discussion}

The trial revealed that in the preparation of the identical foodstuff there were different results in digestion when the foodstuff was salty or sweet, which certainly also resulted from a different chemical composition of salt and sugar. [10] The above-mentioned fact was the reason why different aromata were searched for, namely the salty Niva and sweet tangerine aromata, in order to be able to compare the influence of the so-called salty and sweet stimulation in future.

In the food industry, testing directly on consumers is widely used to find the best readily marketable foodstuffs. [11] The customers themselves thus essentially specify how the final product should taste. Nevertheless, in the case of patients with an organic swallowing disorder the olfactory sensations can be completely different from those of the healthy population. This can be considered a weak point of our testing, and that is why we opted for testing in the form of a sensory panel.

Testing by means of a sensory panel is used in various branches of food industry. For example, testing of instant and freshly ground coffee prepared from the same raw material revealed significant differences, predictably, in favour of freshly ground coffee [12] Also in the set of the olfactory supplements tested, a significant difference between the individual components was demonstrated.

There is a relatively interesting idea of influencing the aroma of dried vegetables. In a trial concerned with the preparation of vegetable food it was recommended to enrich the diet prepared from dried vegetable with the aroma extracted from fresh vegetable. [13] There are also great possibilities of influencing wine aroma. [14] Perhaps the influence on the olfactory sensation by the aroma of fresh vegetable or fruit could produce best results in our patients. Of the presented selection of supplements, tangerine aroma was the most successful.

One of the assumptions, i.e. that males will prefer salty and meat aroma and females the sweet one, has failed to be demonstrated, which, however, corresponds with some data from the literature. On testing various foods, no difference has been found in the gustatory preference of males and females. [15]

One of the mediators which induce the feeling of satiety and satisfaction from the received food in the central nervous system is dopamine. A comparison of the level of dopamine produced in the brain in rats has demonstrated that without olfactory and gustatory stimulation the dopamine level is not increased, and on the other hand, the level of dopamine is increased after stimulation [16]. In the case that aroma and taste are not stimulated during food intake, dopamine level in the brain is not increased. In PEG nutrition, the organism therefore lacks a number of factors which, in addition to nutritional value, is provided by food. Newly, a taste-supporting supplement was tested for persons with food intake disorders [17].

In accordance with the theme "Hunger is a Bad Oncologist" recently discussed by the Clinic of Oncology and Radiotherapy, the authors of the project assume that stimulation of the senses of taste and smell in patients nourished by PEG may result in an improvement of nourishment parameters, quality of life and a decrease in the number of comorbidities resulting from insufficient nourishment or imperfect digestion. The project also dovetails into the concept "Development of the Treatment of Patient with Head and Neck Tumours" announced by the European ORL Society.

\section{Conclusion}

The trial has demonstrated the usability of an olfactory supplement in healthy volunteers. A statistically significant difference has been demonstrated between placebo and olfactory supplements. A sensory panel has selected tangerine aroma as the most pleasant one. Further testing will aim at the research of the support of appetite with the use of the same or a similar preparation.

\section{Declarations}

Conflict of Interest: All authors certify that they have no affiliations with or involvement in any organization or entity with any financial interest (such as honoraria; educational grants; participation in speakers' bureaus; membership, employment, consultancies, stock ownership, or other equity interest; and expert testimony or patent-licensing arrangements), or non-financial interest (such as personal or professional relationships, affiliations, knowledge or beliefs) in the subject matter or materials discussed in this manuscript.

Ethical approval: The manuscript has been approved by Ethical Committee of University Hospital in Hradec Kralove. All procedures performed in studies involving human participants were in accordance with the ethical standards of the institutional and national research committee and with the 1964 Helsinki declaration and its later amendments.

Informed consent: Formal consent is not required for this type of study

Raw data are available in Author.

\section{Acknowledgements}

Supported by Ministry of Health of the Czech Repubic - DRO (UHHK, 00179906) and by Ministry of Education, Youth and Sports of the Czech Republic - ED3.1.00/14.0300.

\section{References}

[1] Mattes, R. D., Physiologic responses to sensory stimulation by food: nutritional implications, J. Am. Diet. Assoc., 97 (4). 406-413. Apr 1997.

[2] Alvarez-Camacho, M. et al., The impact of taste and smell alterations on quality of life in head and neck cancer patients, Qual. Life Res., 25 (6). 1495-1504. Jun 2016.

[3] Mameli, O. \& Melis, F., Olfactory modulation of hypoglossal neuron activity, Arch. Ital. Biol., 131 (2-3). 201-212. Apr 1993.

[4] Mameli, O. et al., Olfactory influence on tongue activity, Arch. Ital. Biol., 133 (4). 273-288. Oct 1995.

[5] Yamamura, K., Kurose, M. \& Okamoto, K., Chemical Sensing Regulates Mastication/Swallowing, Curr. Pharm. Des., 22 (15). 2279-2284. 2016. 
[6] Giduck, S. A., Threatte, R. M. \& Kare, M. R., Cephalic reflexes: their role in digestion and possible roles in absorption and metabolism, J. Nutr., 117 (7). 1191-1196. Jul 1987.

[7] Schriever, V. A. et al., Sniffin' Away the Feeding Tube: The Influence of Olfactory Stimulation on Oral Food Intake in Newborns and Premature Infants, Chem. Senses, 43 (7). 469-474. Aug 2018.

[8] Pedersen, A. M., Bardow, A., Jensen, S. B. \& Nauntofte, B., Saliva and gastrointestinal functions of taste, mastication, swallowing and digestion, Oral Dis., 8 (3). 117-129. Aug 2002.

[9] McGinley, C., McGinley, M. \& McGinley, D. in The 22nd Annual Hawaii Water Environment Association Conference. 1-15 (St. Croix Sensory Inc. / McGinley Associates, P.A).

[10] Oikonomopoulou, V., Karantonis, A., Karathanos, V. T. \& Krokida, M. K., Effect of different processing conditions on release of ingredients in solutions simulating gastric fluid and saliva, Food Research International, 84. 136-142. Jun 2016.

[11] Antunez, L., Vidal, L., de Saldamando, L., Gimenez, A. \& Ares, G., Comparison of consumer-based methodologies for sensory characterization: Case study with four sample sets of powdered drinks, Food Qual. Prefer., 56. 149-163. Mar 2017.
[12] Stokes, C., O'Sullivan, M. \& Kerry, J., Hedonic and descriptive sensory evaluation of instant and fresh coffee products, Eur. Food Res. Technol., 243 (2). 331-340. Feb 2017.

[13] Dubova, H., Yegorov, B., Bezusov, A. \& Voskoboinyk, V., Study of factors affecting developement of food aromatisation, Food Sci. Technol. Bull., 11 (3). 17-24. Aug 2017.

[14] Li, S., Bindon, K., Bastian, S., Jiranek, V. \& Wilkinson, K., Use of Winemaking Supplements To Modify the Composition and Sensory Properties of Shiraz Wine, J. Agric. Food Chem., 65 (7). 1353-1364. Feb 2017.

[15] Weaver, M. R. \& Brittin, H. C., Food Preferences of Men and Women by Sensory Evaluation Versus Questionnaire, Family \& Consumer Sciences Research Journal, 29 (3). 288. Aug 2001.

[16] Yang, Z. J., Meguid, M. M. \& Oler, A., Eating-associated VMNdopamine levels of rats: comparison of oral and intragastric feeding, Neuroreport, 8 (6). 1543-1547. Apr 1997.

[17] Pouyssegur, V. et al., An innovative solid oral nutritional supplement to fight weight loss and anorexia: open, randomised controlled trial of efficacy in institutionalised, malnourished older adults, Age Ageing, 44 (2). 245-251. Mar 2015.

(C) The Author(s) 2019. This article is an open access article distributed under the terms and conditions of the Creative Commons Attribution (CC BY) license (http://creativecommons.org/licenses/by/4.0/). 